\title{
CONTRATAÇÃO DA COOPERAGE - COOPERATIVA DOS AGENTES ECOLÓGICOS - PARA COLETA SELETIVA DO LIXO NO MUNICÍPIO DE CASCAVEL - PROBLEMAS E DESAFIOS
}

\author{
Adilson José Mohr \\ Acadêmico do Curso de Direito da Faculdade de Ciências Sociais Aplicadas de Cascavel. \\ e-mail: adilsonmohr@bol.com.br
}

RESUMO: Cooperativismo: conjunto de princípios e diretrizes que integram o poder público e a sociedade civil na busca de soluções sociais e jurídicas para o enfrentamento da pobreza. Os altos índices de desemprego têm como fator gerador várias causas, entre elas a falta de qualificação profissional gerada pelo analfabetismo. Esta é a realidade no município de Cascavel, em que centenas de famílias vivem à margem da sociedade e cuja sobrevivência depende dos resíduos encontrados no lixo, que podem ser reciclados, permitindo-lhes oportunidade de trabalho e renda. A presente pesquisa faz uma reflexão sobre a problemática da exclusão social, agravada pela pobreza, e sobre como o cooperativismo atua de forma a minimizar o problema. Trata-se de uma análise das previsões legais pertinentes à Constituição Federal, nas legislações ambiental e administrativa, na lei orgânica municipal, entre outras. Cascavel, diante da complexidade de enfrentamento da pobreza, poderá melhorar as condições das famílias que estão organizadas no sistema cooperativo, porém estas necessitam do apoio do poder público para legalização e auto-gestão da Cooperativa dos Agentes Ecológicos (Cooperage). A forma de apoio será a contratação da Cooperage para realização da coleta seletiva do lixo no município - uma oportunidade de geração de emprego e renda que diminuirá o ônus assistencial de Cascavel, proporcionando dignidade às famílias carentes, ou seja, construção de vida com moradia, saúde, educação e trabalho digno.

PALAVRAS-CHAVE: Exclusão social; Capital social; Cooperativismo; Direito ambiental; Direito cooperativo; Lei orgânica municipal. 


\section{INTRODUÇÃO}

A presente pesquisa atém-se ao tema cooperativismo - conjunto de princípios e diretrizes integrando o poder público e a sociedade civil, na busca de soluções sociais e jurídicas para o enfrentamento da pobreza. O objetivo deste trabalho é demonstrar que existe a possibilidade de, em conjunto, o Poder Público, o Poder Legislativo e a sociedade civil elaborarem um projeto de regulamentação do serviço de coleta seletiva de lixo, tendo como prestadora a Cooperage (Cooperativa dos Agentes Ecológicos).

Esta pesquisa focaliza o problema de pessoas que, por um motivo ou outro, estão desempregadas, têm família para sustentar, são excluídas de toda e qualquer oportunidade de emprego digno e sobrevivem de catar produtos encontrados no lixo: resíduos recicláveis depositados nas lixeiras das residências e destinados aos lixões. No município de Cascavel-PR, a população de catadores cresceu tanto que passou a preocupar os moradores e os governantes.

Ao final da década de 1990, em parceria com a Secretaria Municipal do Meio Ambiente, a Secretaria Municipal de Ação Social elaborou o Projeto Ecolixo (Anexo 1), a partir do qual foi construído o Centro de Processamento e Transferência de Materiais Recicláveis (CPTMR). Localizado dentro do Parque Vitória, na Rua Manaus, esquina com a Rua Di Cavalcanti, no Bairro Independência, abrange uma área de 139.962,12 $\mathrm{m}^{2}$, com edificações de 3.654,44 $\mathrm{m}^{2}$. Atualmente, este Centro tem por funções receber, processar, comercializar e embarcar os materiais recicláveis coletados. O Ecolixo possui estrutura e capacidade para receber todos os produtos recicláveis de Cascavel, podendo processar mais de 80 toneladas de materiais ao mês.

Segundo informações da Secretaria de Ação Social, representada pela atual coordenação do Projeto, este apresentou resultados positivos tanto na preservação ambiental quanto na legitimação do trabalho dos catadores, os quais passaram a ser chamados de Agentes Ecológicos.

Até o início da década de 1990, período em que foram iniciados estudos para a implantação do Programa de Coleta Seletiva no município, o rápido crescimento urbano de Cascavel gerava efeitos positivos e negativos para a qualidade de vida da população. O lixo gerado, assim como em outros municípios, acarretava doenças, bem como a contaminação de recursos naturais. $E$ como 
agravante, constataram-se a saturação do aterro sanitário e dificuldades em encontrar nova área na região próxima ao perímetro urbano (ISAM apud. OBLADEN, 2000, p.12).

O crescimento populacional de Cascavel era grande, conforme é possível observar no quadro a seguir:

\begin{tabular}{|c|c|c|c|}
\hline \multirow{2}{*}{ ANO } & \multicolumn{3}{|c|}{ POPULAÇÃO } \\
\cline { 2 - 4 } & Urbana & Rural & TOTAL \\
\hline 1960 & 5.274 & 34.234 & 39.598 \\
1970 & 34.961 & 54.960 & 89.921 \\
1980 & 123.698 & 39.761 & 163.459 \\
1991 & 177.668 & 15.216 & 192.884 \\
1996 & 205.392 & 14.260 & 219.652 \\
\hline
\end{tabular}

FONTE: IBGE apud OBLADEN, 2000, p.07

De acordo com o quadro, a população recenseada em 1960 era de 5.274 habitantes; em 1996, cresceu para aproximadamente 253.000 habitantes, sendo atualmente de 272.243, segundo IBGE (julho-2004).

No final da década de 1990 e começo do ano 2000, teve início a implantação da coleta seletiva do lixo no município de Cascavel. Segundo os idealizadores do Projeto Ecolixo, houve três razões principais para a sua implantação:

1) o custo futuro da coleta e a disposição final seriam reduzidos pela diminuição do volume de resíduos a serem aterrados. O benefício ambiental tornar-se-ia aparente e significativo durante os próximos anos;

2) os impactos ambientais causados pelos poluentes sobre $o$ ar e as águas seriam reduzidos na proporção da diminuição do consumo de produtos e materiais virgens e de energia;

3) o desenvolvimento econômico com a criação de novos empregos pela expansão dos negócios relativos à reciclagem e a geração de novos empreendimentos era visível.

Com a oportunidade do Projeto, os agentes ecológicos, tratados como massa de manobra e exploração econômica dos compradores de materiais recicláveis, passaram a ser tratados com dignidade e a receber o justo pelo trabalho prestado. Além disso, receberam apoio quanto a assistência social, acidentes do 
trabalho e conscientização da comunidade para colaboração na separação dos resíduos.

Em 2004, foi criada em Cascavel a Cooperage (Cooperativa dos Agentes Ecológicos) como forma de proporcionar trabalho, renda e inclusão social às famílias associadas ao Ecolixo.

Trata-se, ainda, de uma cooperativa informal de trabalhadores que precisa ser legalizada, principalmente pela questão comercial, para se tornar uma sociedade com personalidade jurídica própria, instituída com base na lei 5.764/71, que define a política nacional do cooperativismo.

O Projeto Cooperage teve seu início em forma de associação com o nome de Acamar (Associação dos Catadores de Materiais Recicláveis de Cascavel). A participação da Acamar nos Fóruns Regionais do Programa Lixo \& Cidadania, desenvolvido pelo governo estadual, estimulou a intenção de transformar a associação existente em cooperativa, tendo em vista a conquista de uma forma mais democrática de participação, em que há o direito de voz e voto.

Além disso, a cooperativa proporcionaria aos cooperados a oportunidade de comercialização dos materiais diretamente com a indústria, eliminando os intermediários do processo, possibilitando a divisão das sobras entre os próprios cooperados, e, ainda, poderia participar da licitação para coleta seletiva do lixo em Cascavel. Este conjunto de ações resultaria na formação de capital social na sociedade. ${ }^{1}$

Assim, surge a questão que embasa esta pesquisa: pode o Poder Público Municipal autorizar a concessão para exploração da coleta seletiva do lixo pela Cooperage no município de Cascavel-PR?

Para o problema apresentado, têm-se as seguintes hipóteses: a) sim, após a sua formalização e legalização, a Cooperativa poderá firmar um contrato com o Poder Público Municipal de Cascavel na forma de concessão, mediante licitação; b) não, a Cooperage não poderá ser contratada pelo Poder Público Municipal para a realização da coleta seletiva do lixo, pois para efetuar a contratação necessita-se de licitação, então como cooperativa não poderá participar.

1 Trata-se da capacidade de cooperação e convivência comunitária das pessoas. Seu requisito principal é a confiança mútua entre instituições públicas, privadas e população, ou seja, atitudes éticas e democráticas formarão o capital social, que é um dos caminhos na luta contra as desigualdades sociais. 
Com base no problema apresentado e nas hipóteses conclusivas, trabalhouse para atender ao objetivo geral, que restringe-se a analisar juridicamente o Projeto Ecolixo e a Cooperage para verificar se esta poderá no futuro contratar com o Município de Cascavel a coleta seletiva do lixo. Para tanto, a pesquisa ateve-se aos seguintes objetivos específicos:

4) levantar informações sobre como montar uma cooperativa popular;

5) apurar dados para a legalização de cooperativas;

6) pesquisar nas legislações federal e municipal as previsões legais referentes à possível contratação da Cooperage com o município de Cascavel;

7) analisar quais são os benefícios da coleta seletiva do lixo para a sociedade e o meio ambiente, com base no Direito Ambiental;

8) identificar os benefícios que o possível contrato entre o município de Cascavel e a Cooperage proporcionará aos cooperados.

Como justificativa para a escolha do tema e a delimitação do problema está seu tema central, que é o cooperativismo e seus princípios básicos: a divisão igualitária, o bem comum e a coletividade. Vários exemplos demonstram, no Brasil e no mundo, que o trabalho organizado nesse sistema mostra-se muito eficaz. Como forma de confirmação, pode-se até mesmo citar o próprio Projeto Ecolixo e a Cooperage, objetos deste estudo. Ao analisar sua atual situação, é possível perceber que, após a implantação, que objetivava melhores condições de vida às várias famílias dependentes da coleta seletiva do lixo no município, os dois projetos estão no caminho certo, permitindo atualmente oportunidade de emprego e renda às famílias que estavam à margem da sociedade e a descentralização e diminuição do ônus assistencial ao poder público. Porém, uma das possibilidades de melhorias apontadas é a contratação da Cooperage pelo Poder Público para executar o serviço de coleta seletiva do lixo no município. Não se trata de um assunto comum, pois o País não possui uma história muito vasta ao que se refere ao cooperativismo, e é nesse sentido que este trabalho se torna importante à Ciência do Direito, à faculdade e ao pesquisador, pois analisará as possibilidades existentes no ordenamento jurídico para a contratação desta cooperativa - resultado de um projeto social do próprio município - para executar um serviço à sua fonte criadora. Assim, também a Faculdade estará cumprindo seu papel social, haja vista que os 
resultados da presente pesquisa poderão ser usados como argumentos pelos cooperados da Cooperage, como instrumento de luta para a sua implantação.

Em aspectos técnicos-metodológicos, esta pesquisa pode ser classificada como:

1) Pesquisa descritiva - apresenta uma reflexão sobre a problemática da exclusão social, amparada pela idéia da pobreza, e mostra como o cooperativismo poderá atuar de forma a solucionar o problema. Tem como foco a Cooperage, em Cascavel-PR.

2) Estudo de caso: analisa o Projeto de Coleta Seletiva do Lixo no município de Cascavel-PR e a Cooperativa dos Agentes Ecológicos.

3) Pesquisa bibliográfica: foram estudados a Constituição Federal, a Legislação Ambiental e Administrativa, a Lei Orgânica Municipal e demais autores.

\section{O PROJETO ECOLIXO E A PROTEÇÃO AO MEIO AMBIENTE EM CASCAVEL}

O município de Cascavel conta com uma estrutura excelente para realização da coleta seletiva do lixo, porém o Ecolixo, com o Centro de Processamento e Transferência de Materiais Recicláveis, atualmente está aquém da sua capacidade de produção, pois o mesmo foi construído para receber e processar todo o material reciclável gerado no Município.

Segundo dados informados pelo Engenheiro Químico Elmo Rowe Júnior, responsável pela divisão de resíduos sólidos do aterro sanitário, é recolhida e depositada uma média de 200 toneladas por dia de lixo no aterro, das quais $30 \%$ a $35 \%$ são de resíduos recicláveis. Por isso a importância de melhorar a coleta seletiva do lixo, por meio do incentivo do sistema cooperativo em que estão organizados os catadores.

De acordo com informações prestadas no mês de abril de 2005, por Marilda Thomé Paviani, coordenadora do projeto Cooperage, existem atualmente cerca de 450 catadores de materiais recicláveis no município, porém estima-se que possam estar trabalhando nessa área mais de 800 pessoas. Com esses números, indiretamente cerca de 4.000 pessoas sobrevivem da coleta de materiais recicláveis, 
considerando que as famílias estejam constituídas com uma média de cinco pessoas por família.

Nesse contexto, torna-se viável ao município realizar a cessão de uso do complexo Ecolixo para a Cooperage e regulamentar o serviço de coleta seletiva do lixo, firmando um contrato de concessão de serviço público permitindo à cooperativa a realização da coleta seletiva em todo o município. Esta regulamentação poderá contemplar todas as famílias que trabalham na coleta de produtos recicláveis, permitindo-Ihes organização, planejamento, melhores condições de trabalho, aumento na renda financeira e reconhecimento como categoria profissional. $O$ município, por sua vez, estará incentivando o cooperativismo, e a partir de um projeto-piloto poderá estendê-lo a outros segmentos e formas de trabalho além da coleta seletiva do lixo.

Trata-se de um projeto de interesse social no sistema cooperativo e que necessita de normas legais para se tornar realidade. Nesse sentido, o Poder Legislativo é fator importante, em virtude de ser o poder responsável pela elaboração de projetos que venham de encontro aos interesses da população, bem com do município. A produção legislativa deve ser adequada, conforme destaca Namorado (2000):

A atividade cooperativa é uma prática quotidiana impregnada, em maior ou menor grau, pela aspiração a uma sociedade diferente, pelo que incorpora em si própria uma tensão, que só poderá ser fecunda se dispuser de um enquadramento jurídico que impeça de se transformar numa pulsão dissipativa, dando-lhe assim equilíbrio e consistência. E é, precisamente, a importância desse enquadramento que permite compreender que um dos fatores que mais facilmente prejudica o sector cooperativo seja uma produção legislativa inadequada.

O autor português refere-se à legislação no sentido de normas gerais, que um Estado deve elaborar para o incentivo ao cooperativismo. Seguindo esta linha de raciocínio, o Poder Legislativo do município, ao elaborar lei regulamentando o serviço da coleta seletiva em favor das famílias carentes, estará incentivando também o cooperativismo, que poderá ser estendido a outras formas de trabalho.

A geração de resíduos sólidos possíveis de serem reciclados cresce a cada dia, em razão do consumo cada vez maior de produtos industrializados. No entanto, a destinação dos mesmos ainda não é adequada. Um dos motivos é a falta de leis que incentivem a reciclagem. A Lei Federal 2.312/54 dispõe, sobre normas gerais, 
sobre defesa e proteção à saúde. Em seu artigo 12 dispõe que: "A coleta, 0 transporte e o destino final do lixo deverão processar-se em condições que não tragam inconvenientes à saúde e ao bem estar público."

O artigo 30, inciso v, da Constituição Federal diz que: "Compete aos Municípios: organizar e prestar, direta ou sob regime de concessão ou permissão, os serviços públicos de interesse local." Portanto, os municípios têm legitimidade para criar leis de incentivo à coleta seletiva, bem como a concessão do serviço.

Uma das principais leis ambientais é a Lei 6.938/81, que trata da Política Nacional do Meio Ambiente. Esta Lei define que o poluidor é obrigado a indenizar os danos ambientais que causar, independentemente de culpa. O Ministério Público pode propor ações de responsabilidade civil por danos ao meio ambiente. Também, esta lei criou os Estudos e Respectivos Relatórios de Impacto Ambiental (EIA/RIMA), regulamentados em 1986 pela Resolução 001/86 do Conselho Nacional do Meio Ambiente (Conama).

Preservar o meio ambiente significa proteger a vida. Nesse sentido, este capítulo, neste item, identificou a importância da coleta seletiva do lixo como forma de preservação ambiental e que deve haver integração entre os poderes públicos e a sociedade civil para a efetiva concretização dos objetivos propostos. No próximo item, analisaremos os benefícios sociais e o sistema cooperativo.

\section{AÇÃO SOCIAL E O PROJETO DA COOPERAGE PARA INCLUSÃO SOCIAL (CAPITAL SOCIAL, DEFINIÇÃO DE COOPERATIVA, AÇÃO SOCIAL)}

A globalização trouxe vantagens relacionadas à eficiência na queda dos preços, em termos de desenvolvimento tecnológico e de qualidade dos produtos, mas trouxe também vários aspectos negativos para a vida social. Segundo Nazzari, Silva e Lazzarotto (2004, p.7), "[...] com a globalização intensificou-se, por exemplo, a concentração e a centralização geradora de exclusão social." A concentração dos investimentos das empresas nos setores em que atuam e a centralização ou incorporação pelas grandes das pequenas empresas, abaladas com a concorrência acentuam cada vez mais as desigualdades entre as diversas regiões.

Assim, para Nazzari, Silva e Lazzarotto (2004, p.7-8), "[...] Com a globalização se acentua não só as desigualdades nos níveis renda, mas também - 0 
que é mais grave - as taxas de desemprego, o nível dos salários, a deterioração das condições de trabalho etc."

Nesta direção, observa-se a importância da distinção entre a nova e velha exclusão, observada por Pochmann (2001) apud NAZZARI (2004): enquanto a velha exclusão baseava-se nos baixos índices de escolaridade, no analfabetismo e no nível de renda como indicadores de exclusão social, na nova acrescentam-se outros indicadores ligados às condições de vida das pessoas.

[...] levando em conta os aspectos negativos do mundo globalizado, na definição de exclusão social deve-se considerar não só os níveis de escolaridade, de analfabetismo e de renda das pessoas, mas também os níveis de violência, de desigualdade, de emprego formal, de acesso à saúde, à habitação, ao lazer, entre outros fatores que afetam a vida das pessoas nos diversos países, regiões ou agrupamentos sociais (NAZZARI, SILVA e LAZZAROTTO, 2004, p.8).

Sabe-se que comunidades com índices elevados de capital social ${ }^{2}$ podem encontrar alternativas eficazes para a superação da exclusão social e o desenvolvimento econômico. Para

[...] enfrentar as condições estruturais adversas da economia que levam à exclusão social vedando aos pobres o acesso ao mercado de trabalho [...] e ao acesso de elementos materiais básicos é de fundamental importância para a existência da vida humana, tais como: saúde, educação e lazer." (RATTNER, 2004, p.3, apud NAZZARI).

Em uma sociedade classista e capitalista, em que valores como solidariedade, cooperação e confiança são deixados de lado e substituídos por sentimentos de competitividade e desconfiança, fica cada vez mais difícil organizar grupos cooperativos e atuantes. Os estudiosos enfatizam a correlação entre o grau de confiança geral e as normas de cooperação prevalecentes na sociedade. Assim, destaca-se que, quanto menores as diferenças entre ricos e pobres, maior é o capital social, mais ampla é a participação em associações, melhor é a renda e melhores as práticas produtivas, na agricultura e na indústria. Dessa forma, a

2 A partir dos estudos de Tcqueville sobre a democracia e o associativismo civil norte-americano, posteriormente, "[...] Bourdieu, James Coleman, Robert Putman, Francis Fukuyama, entre tantos outros cientistas sociais", cada um, à sua maneira, contribuiu para o entendimento do conceito de capital social. Assim, pode ser visto como "[...] confiança mútua e institucional e predisposição para a cooperação e participação cívica - constitui um dos fatores que podem influenciar decisivamente o processo de promoção do bem-estar social". (apud NAZZARI, SILVA e LAZZAROTTO, 2004, p.8). 
cooperação com a administração pública melhora a qualidade dos serviços públicos na educação, na saúde, entre outros.

Segundo Fukuyama,

A função política do capital social é ajudar a democracia na "arte da associação". A propensão para ao associativismo e a participação em associações voluntárias colabora para combater o individualismo. Juntos, associações civis fortes e interesses individuais fracos, começam a fortalecer a participação das pessoas na vida política. Tal como partidos políticos e interesses de grupos podem servir como escola de cidadania quando incentivam hábitos de cooperação que podem eventualmente incrementar os interesses na vida pública. "A sociedade civil prepara-se para balançar o poder do Estado e proteger os indivíduos. Assim, o capital social é vital para o funcionamento formal das instituições públicas" (FUKUYAMA apud NAZZARI, 2003, p.58).

O capital social foi uma conseqüência da capacidade de cooperação e convivência comunitária das pessoas, além de servir como uma ponte alternativa multidisciplinar para redefinir as relações entre o Estado e a sociedade, apontando para formas de participação políticas diferentes dos padrões tradicionais de comportamento político.

Nesta direção, "[...] O capital social sustenta que a participação em associações voluntárias gera normas de cooperação e confiança entre os seus membros e que essas normas são aquelas exigidas para a participação política" (BAQUERO, 2001, p.36).

Uma das formas para valorização do capital social e fortalecimento da confiança nas instituições públicas é o movimento cooperativo. De acordo com Namorado (2000, p.11), "a noção de cooperativa exprime em si própria uma metamorfose, sendo um novo caminho para a evolução da sociedade no combate às diferenças sociais entre as classes."

Reafirmando o que destaca Nazzari (2003), a elevação dos índices de capital social é condição fundamental como alternativa para o resgate social e ampliação da qualidade de vida das classes historicamente excluídas.

Segundo Rodrigues (2001, p.32), o cooperativismo é uma fonte para o capital social, seja porque é uma doutrina baseada em princípios universais regidos pela solidariedade, seja porque faz negócios. Segundo Nazzari; Reule e Lazzarotto (2003 p.25), a partir dessa correlação entre capital social e cooperativismo, pode-se desencadear o desenvolvimento sustentável local. 
A Constituição deve ser a mais importante fonte de diretrizes dos governos. A vedação da interferência estatal sobre o funcionamento das cooperativas indica grande potencial de desenvolvimento para o cooperativismo. A promulgação do novo texto constitucional altera o panorama jurídico do cooperativismo. $O$ art. 5응 inciso XVIII, prevê "a criação de associações e, na forma da lei, a de cooperativas independem de autorização, sendo vedada a interferência estatal em seu funcionamento".

$\mathrm{Na}$ sua origem, o movimento cooperativo foi um dos aspectos da emergência do movimento operário, sendo, por isso, naturalmente impregnado de valores que levaram ao inconformismo perante as desigualdades sociais, a injustiça e a opressão. Segundo Namorado (2000, p.15):

Características essenciais de uma cooperativa estão no fato de ela ser: "uma associação de pessoas que se agrupam voluntariamente para atingir um fim comum, através da constituição de uma empresa dirigida democraticamente, fornecendo uma quota-parte equitativa do capital necessário e aceitando uma justa participação nos riscos e nos frutos dessa empresa, no funcionamento da qual os membros participam ativamente". (Recomendação 127/1966, Organização Internacional do Trabalho (OIT).

A figura 1 apresenta a evolução quantitativa das cooperativas por década de fundação. A partir do final da década de 1980, o cooperativismo brasileiro avançou de maneira extraordinária: de 706 para 3.340 em 1999 e para 7.026 em 2001, segundo dados da OCB (Organização das Cooperativas Brasileiras). Ou seja, o aumento foi quase quatro vezes maior.

FIGURA 1 - EVOLUÇÃO QUANTITATIVA DAS COOPERATIVAS POR DÉCADA DE FUNDAÇÃO

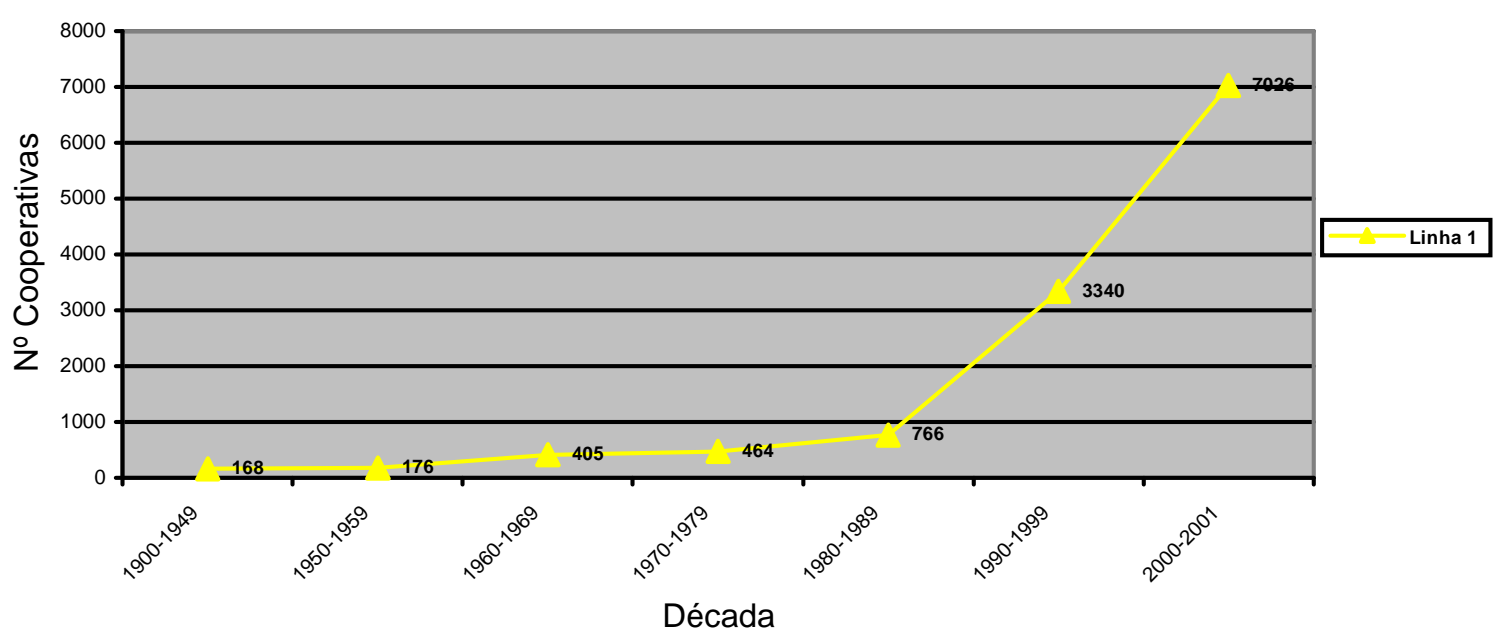


Fonte: (NÚCLEO DE BANCO DE DADOS DA OCB 2001) apud NAZZARI, 2003; p.45.

Estes avanços devem-se principalmente à autonomia conquistada com a atual Constituição de 1988: livre da tutela do Estado, o cooperativismo brasileiro ampliou seus horizontes.

Segundo a Lei 5.764, de 16/12/71, a cooperativa é "uma sociedade de pessoas, com forma e natureza civil, não sujeita a falência, constituída para prestar serviços aos associados".

Pode-se definir uma cooperativa como uma associação voluntária de no mínimo 20 pessoas, sem fins lucrativos, porém com fins econômicos, que exercem uma mesma atividade para realizar objetivos comuns e, para tanto, contribuem eqüitativamente para a formação do capital necessário por meio de aquisição de quotas-partes e aceitam assumir de forma igualitária os riscos e benefícios do empreendimento. É regida pelo princípio democrático de cada pessoa um voto. Os excedentes ou sobras são distribuídos na proporção do trabalho de cada cooperado.

O direito cooperativo deve ser entendido como o processo de contribuição para a ampliação dos índices de inclusão social de uma comunidade, ampliando as bases legais para reforçar o papel do direito junto às políticas sociais, ampliando a participação da população. É a procura de amparo legal para colaborar na diminuição da exclusão social, bem como propiciar alternativas municipais para a "[...] descentralização das ações político-administrativas com a adequada distribuição de poderes político e financeiro. É desburocratizante, participativa, não autoritária, democrática e desconcentradora do poder (JOVCHLOVITCH, 2003, p.2).

Dentro do ordenamento jurídico brasileiro, há várias leis que servem de diretrizes para os poderes públicos Federal, Estadual e Municipal elaborarem projetos na área social que atendam às dificuldades das classes pobres da

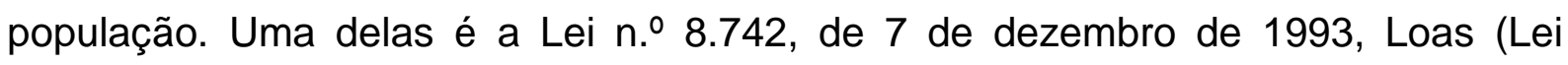
Orgânica da Assistência Social), que regulamenta os arts. 203 e 204 da Constituição Federal. Esta Lei prescreve em seu artigo 1.que:

A assistência social, direito do cidadão e dever do Estado, é Política de Seguridade social não contributiva, que prevê os mínimos sociais, realizando através de um conjunto integrado de ações de iniciativa pública e da sociedade, para garantir o atendimento às necessidades básicas. 
Esta pesquisa busca demonstrar a importância da integração entre poder público, poder político e sociedade civil na busca de soluções que venham ao encontro dos interesses sociais. Neste sentido, o artigo 2.ำ parágrafo único da Loas indica que

A Assistência social realiza-se de forma integrada às políticas setoriais, visando ao enfrentamento da pobreza, à garantia dos mínimos sociais, ao provimento de condições para atender contingências sociais e à universalização dos direitos sociais.

O artigo 25 da Lei n8.742/93, Lei Orgânica da Assistência Social, trata dos projetos de enfrentamento da pobreza. Neste artigo está a base legal que indica a viabilidade da idéia central deste projeto, que é a possível contratação da Cooperage pelo município de Cascavel para realização da coleta seletiva do lixo no município.

Os projetos de enfrentamento da pobreza compreendem a instituição de investimento econômico social nos grupos populares, buscando subsidiar, financeira e tecnicamente, iniciativas que the garantam meios, capacidade produtiva e de gestão para melhoria das condições gerais de subsistência, elevação do padrão da qualidade de vida, a preservação do meio ambiente e sua organização social.

Seguindo as diretrizes da Lei Federal n. 8.742/93, o município de Cascavel elaborou a Lei Municipal n. 2.520/95, Lei Orgânica da Assistência Social, que tem suas definições e objetivos elencados no artigo 1.o.

A assistência social, direito do cidadão e dever do Estado, é política de seguridade social não contributiva, que prevê os mínimos sociais, realizada através de um conjunto de ações da iniciativa pública e da sociedade, para garantir o atendimento às necessidades básicas da população.

Nota-se aqui, mais uma vez, o caráter de integração social. A lei municipal contempla em seu artigo $2^{\circ}$, inciso v, como objetivo s: "A promoção de projetos de enfrentamento da pobreza".

Os municípios precisam de um arcabouço jurídico-institucional na área do meio ambiente e do cooperativismo que venha a reafirmar a titularidade municipal dos serviços garantida pelo art. 30, inciso v, da Constituição Federal:

(...) fortalecer os princípios de função social dos serviços públicos e o atendimento universal, bem como dar prioridade a investimentos nessas áreas, visando ampliar a 
cobertura dos serviços e contribuindo para reduzir a dívida social, bem como destacando sua prioridade enquanto política pública social.

A normalização e o controle dos serviços públicos nas áreas de saneamento e meio ambiente devem contemplar aspectos cooperativistas, porque as entidades governamentais ou privadas, responsáveis pela execução outorgada dos serviços públicos, geralmente exercem de tal modo o monopólio técnico e financeiro desses serviços que não dão espaço suficiente para o exame, a discussão e a avaliação dos reais interesses da comunidade de usuários, nem mesmo do Poder Público concedente. A situação se inverte perversamente ao ficar a realização dos serviços subordinada às normas e ao controle estabelecidos pela própria concessionária, ou seja, a entidade concessionária executa os serviços e os normatiza e controla ao mesmo tempo.

O poder público não raro se vê-impotente diante desta usurpação indevida e ilegítima dos bens coletivos. Assim, a contrastabilidade imprescindível ao processo de fiscalização e controle dos serviços com dispositivos legais, bem como a transparência na execução e alocação dos recursos da área podem contribuir com projetos de inclusão social das famílias pobres.

Nesse sentido, torna-se necessário o estabelecimento de mecanismos e processos institucionais-legais apropriados a cada realidade local que possibilitem um real e democrático controle por parte do poder público e da comunidade de usuários sobre a execução dos serviços. Isto, é claro, implica uma efetiva e adequada reforma administrativa que ajuste o papel de cada agente governamental envolvido, e de todos integralmente, imputando-lhes claramente competências normativas, de controle e executivas no apoio às atividades cooperativistas, bem como as dimensões e efetividade da participação dos usuários nessa regulação, controle e execução.

\section{A CONTRATAÇÃO DA COOPERAGE PELO MUNICÍPIO DE CASCAVEL PARA A COLETA SELETIVA DO LIXO}

A proposta é desafiadora em razão dos interesses econômicos que estão em jogo: de um lado, temos interesses dos empresários que exploram esta atividade; do outro, o poder público e os catadores, que realmente necessitam de ajuda para sobrevivência, são famílias carentes e dependentes dos produtos 
recicláveis, visto que se trata da sua única fonte de renda. A solução para estas questões pode ser simples, desde que o poder público esteja empenhado e cumprindo sua função, que é a de garantir o bem-estar da população. Entretanto, haverá a necessidade de um conjunto de ações entre os poderes Executivo e Legislativo, pois para concretização do projeto, obrigatoriamente, este deverá passar por aprovação na Câmara Municipal.

Após autorização da Câmara Municipal, à contratação da Cooperage com o município, esta deverá ser outorgada pelo Prefeito apor meio de decreto, conforme o artigo 172 da Lei Orgânica Municipal:

A exploração de serviço público a título precário será outorgado por decreto do Prefeito, após edital de chamamento de interessados para a escolha do melhor pretendente, mediante contrato precedido de concorrência pública.

A Cooperage está em processo de legalização e não possui sede própria. Atualmente, faz uso da estrutura do Ecolixo, o qual é patrimônio público municipal. Diante disso, além de o município de Cascavel contratar a Cooperage para realização da coleta seletiva do lixo, poderá também outorgar uma concessão de direito de uso de toda a estrutura do Ecolixo. Para tanto, a Lei Orgânica Municipal, no seu Capítulo IX, determina normas sobre os Bens Municipais:

Artigo 166 - O município outorgará concessão de direito de uso, preferencialmente à venda ou doação de seus bens imóveis, mediante autorização legislativa e concorrência pública.

Chama a atenção a questão da concorrência pública, de que, conforme o art. 166, a Cooperage, para contratar com o poder público, teria que participar. Porém, entende-se que, por se tratar de um relevante interesse público, a contratação da Cooperage poderá ser dispensada de concorrência, com base no art. 166, $\S 1^{\circ}$ da Lei Orgânica Municipal, que prescreve a seguinte norma:

A concorrência poderá ser dispensada por lei, quando o uso se destinar a concessionária de serviços públicos e entidades assistenciais, ou quando houver relevente interesse público devidamente justificado.

Neste caso, justifica-se pelo relevante interesse público, ou seja, o benefício às famílias dos catadores de papel, que terão emprego e renda garantidos, redução do ônus assistencial por parte do município a estas famílias, preservação do meio ambiente com a diminuição considerável de produtos recicláveis, os quais sem a 
coleta seletiva tem como destino os rios. Outro benefício fundamental será o prolongamento da vida útil do aterro sanitário.

De acordo com a legislação federal e municipal, a solução para o problema apresentado torna-se viável, necessitando apenas que os poderes públicos do município de Cascavel elaborem normas para a regulamentação do serviço de coleta seletiva do lixo. Estrutura adequada para este projeto existe - Ecolixo. Os catadores estão organizados no sistema de cooperativa, fundaram a Cooperage. Neste contexto, com incentivo do poder público e a participação da sociedade colaborando com a separação do lixo nas residências, haverá preservação do meio ambiente e inclusão social das famílias que vivem à margem da sociedade.

\section{CONCLUSÃO}

No que se refere ao problema inicial desta pesquisa, é possível afirmar, dentro de parâmetros legais, que o município de Cascavel poderá contratar a Cooperage (Cooperativa dos Agentes Ecológicos) para realização da coleta seletiva do lixo, desde que a mesma esteja totalmente legalizada.

O cooperativismo é um sistema valorizado mundialmente. No entanto, há um longo caminho a ser percorrido, até que seja reconhecido o seu justo valor como ferramenta do desenvolvimento econômico e social sustentável. A grande barreira está na falta de conhecimento por parte, principalmente, dos governantes, que muitas vezes ignoram as iniciativas de projetos no sistema cooperativo sem uma avaliação prévia dos resultados positivos. Segundo Gediel (2001, p.25):

Tendo em vista o pequeno número de cooperativas que estabelecem uma relação com empresas que possuem um capital acionário, tendo em vista o fato do modelo de cooperativas não ser tratado em cursos superiores e, portanto, o pouco conhecimento dessa matéria por parte dos atores socioeconômicos, torna-se evidente porque as cooperativas são abandonadas à sua própria sorte, e até mesmo ignoradas. Se acrescentarmos ainda o fato de trabalharem com um grupo de trabalhadores, e não com proprietários (possuidores do capital e, portanto, do conhecimento), fica fácil compreendermos porque, para muitas pessoas, as cooperativas de trabalho são uma espécie de "doença" que deve ser evitada a qualquer preço.

A preservação do meio ambiente é compromisso de todos, visto que todo ser humano contribui diariamente na geração de resíduos descartáveis. O mundo 
globalizado impulsiona a produção cada vez maior de produtos descartáveis, ao passo que sua disposição final não tem merecido a atenção adequada por parte da população mundial. Está em tramitação no Congresso Nacional um projeto de lei que, se aprovado, obrigará todo município com mais de cem mil habitantes a implantar a coleta seletiva do lixo. O município de Cascavel implantou a coleta seletiva no ano de 2000, mediante o Projeto Ecolixo, o qual possui estrutura com capacidade para receber e processar todo o material reciclado gerado na cidade.

Este Projeto gerou muitos benefícios ao meio ambiente, bem como às famílias que trabalham na coleta dos materiais recicláveis. No entanto, há a necessidade de melhorias, tanto no Projeto Ecolixo quanto no apoio que o Poder Público tem disponibilizado à Cooperage. A cooperativa está em processo de legalização, faltando apenas os registros legais para adquirir personalidade jurídica e poder realizar contratos e transações comerciais.

A cooperativa precisa de uma sede para desenvolver o trabalho. Atualmente, usa a estrutura do Ecolixo - este, que é um bem público, poderá ser disponibilizado à cooperativa na forma de cessão de uso. Esta possibilidade poderá tornar-se realidade, em razão da estrutura de que o município dispõe para realizar a coleta seletiva do lixo e, ao mesmo tempo, organizar todos os catadores no sistema cooperativo. Dessa forma soluciona-se grande parte dos problemas sociais vividos por esta população carente, gerando reflexos positivos na preservação ambiental, oportunidade de emprego e renda, educação e diminuição do ônus assistencial.

Neste contexto, o sistema cooperativo torna-se fator importante na geração de mudança de comportamento, por meio do convívio social e solidário. Não significa dizer que é a solução ideal para o problema apresentado, entretanto, em uma sociedade cada vez mais competitiva, as boas oportunidades estão restritas a apenas parte da população. Urge a necessidade de despertar no meio social sentimentos de ajuda mútua e solidariedade, princípios do cooperativismo que ajudarão a diminuir a exclusão social, com mais oportunidades de emprego e renda. Neste processo, todos os segmentos sociais têm um lugar garantido e uma tarefa a cumprir, dependendo apenas do nível de consciência humana de cada um para trabalhar e conservar o presente, construindo um futuro melhor. 


\section{REFERÊNCIAS BIBLIOGRÁFICAS}

BAQUERO, Marcello. Reinventando a Sociedade na América Latina: cultura política, gênero exclusão e capital social. Porto Alegre. UFRGS, 2001, p. 19-49.

CONCEIÇÃO, Márcio Magera. Os Empresários do Lixo: um paradoxo da modernidade. Campinas, SP: Editora Átomo, 2003.

CONSTITUIÇÃO FEDERAL/1988.

GASPARINI, Diogenes. Direito Administrativo. 9. ed. São Paulo: Saraiva, 2004.

GEDIEL, José Antonio Peres. Os Caminhos do Cooperativismo / José Antonio Peres Gediel, (Org.)...[et al.]. - [Curitiba]: Editora da UFPR, [2001].

IRION, João Eduardo Oliveira. 1929 - Cooperativismo e Economia Social. São Paulo: Editora STS, 1997.

LEI 5764/71 - Define a Política Nacional do Cooperativismo.

LEI ORGÂNICA DO MUNICÍPIO DE CASCAVEL.

Lei n. 8.742, de 7 de Dezembro de 1993. Lei Orgânica da Assistência Social que regulamenta os artigos 203 e 204 da Constituição Federal.

MANCE, Euclides André. Como organizar redes solidárias. Rio de Janeiro: DRI, 2002.

NAMORADO, Rui. Introdução ao Direito Cooperativo. Portugal: Livraria Almedina - COIMBRA, 2000.

NAZZARI, Rosana Katia. Capital social, cultura e socialização política: a juventude brasileira. Tese de Doutorado em Ciência Política. Universidade Federal do Rio Grande do Sul. Porto Alegre: UFRGS, 2003.

OBLADEN, Nicolau L. (Org.). Programa de Coleta Seletiva e Reciclagem. ECOLIXO. Vamos Separar Juntos. ISAM/PUCPR. 2000.

OCB - Organização das Cooperativas Brasileiras. Dados sobre o Cooperativismo no Brasil. Disponível: www.ocb.org.br. Acesso: em 26 de out. 2003. 17

PERES, Fernando Curi. Capital Social: a Nova Estrela do Crescimento Econômico, 2000, Disponível: http://pa.esalq.usp.br, Acesso em 06 de novembro de 2002.

POCHMANN, Marcio. A exclusão social no Brasil. São Paulo: Bomtempo Editorial, 2001.

RATTNER, Henrique. Sobre a exclusão e políticas de inclusão. Disponível: www.espacoacademico.com. Acesso em 07 de março de 2004.

REULE, Eronice. A influência do capital social e do cooperativismo no desenvolvimento sócio econômico brasileiro. Monografia de Graduação em Ciências Econômicas. Universidade Estadual do oeste do Paraná - Unioeste, Cascavel, 2002. 
RODRIGUES, Roberto. A Segunda onda cooperativa, SESCOOP Serviço Nacional de aprendizagem do Cooperativismo, Dinâmica, 2001.

SINGER, Paul. 1932 - Globalização e Desemprego: Diagnóstico e Alternativas. 3. ed. São Paulo: Contexto, 1999.

SIRVINSKAS, Luis Paulo. Manual de Direito Ambiental. 2. ed. São Paulo: Saraiva, 2003. 